\title{
LANGUAGE PICTURE OF THE WORLD AND ASSOCIATIVE LEXICOGRAPHY
}

\author{
Natalya V. Ufimtseva \\ Institute of Linguistics, Russian Academy of Sciences, Moscow, Russia \\ Olga V. Balyasnikova \\ Institute of Linguistics, Russian Academy of Sciences, Moscow, Russia; \\ Sechenov First Moscow State Medical University, Moscow, Russia
}

\begin{abstract}
Conceptually, the language picture of the world is defined as the representation of the real world in the system of concepts and categories of the language. Language processes (e.g., nomination) are inextricably related to the processes of identifying objects from the outside world and their understanding.

The three interdependent basic concepts, culture, activity, and language consciousness, are implied to reflect the activity which is preconditioned by the system of cultural regulators and the expression of these relations in communication by means of units and language categories.

The Moscow psycholinguistic school, grounded in the speech activity theory, regards the world picture as a system phenomenon in the consciousness of a language speaker / culture bearer, interprets meaning as an ideal form for the objective world to exist, and specifies optimal methods to register the knowledge behind the word in ordinary consciousness of a native language speaker / culture bearer are specified. Among the methods applied, the authors use the free associative experiment to collect data from numerous respondents, speakers of the national language/ members of a cultural community.

The associative and verbal network, built on mass associative experiments, reflects the systematic connections between its elements, i.e. words, each of them, in its turn, has its meaning and systematicity. The comparison of the language picture of the world fragments, the model components allows to make conclusions on the discrepancy both between meanings (knowledge behind the words) of components and their systematicity. Thus, the associative and verbal network as an integral model of the language picture of the world is capable of reflecting elements in the system at micro and macro levels estimating the meaning and significance of each system element.

The advent of associative lexicography has made it possible to obtain the first ever comprehensive model of the world picture from a "naïve" native language speaker / a culture-bearer, and to observe the real interaction and interdependence between the meaning and significance of a separate word within the entire associative verbal network and the associative field.

The data of mass associative experiments reflect the real state of everyday consciousness of a speaker / bearer of a certain language / culture. This evidence is used to analyze the synchronous state of consciousness, as well as to register changes that develop diachronically, given the data were collected at definite time periods. The observed changes indicate shifts in the associative verbal network structure along with the changes in the content $\infty$ of the knowledge associated with the word stimulus, thus reflecting the evolution of the society.

Key words: picture of the world, language picture of the world, category of activity, associative and verbal network, associative thesaurus, meaning, significance.

Citation. Ufimtseva N.V., Balyasnikova O.V. Language Picture of the World and Associative Lexicography. Vestnik Volgogradskogo gosudarstvennogo universiteta. Seriya 2, Yazykoznanie [Science Journal of Volgograd State University. Linguistics], 2019, vol. 18, no. 1, pp. 6-22. (in Russian). DOI: https://doi.org/10.15688/jvolsu2.2019.1.1
\end{abstract}




\title{
ЯЗЫКОВАЯ КАРТИНА МИРА И АССОЦИАТИВНАЯ ЛЕКСИКОГРАФИЯ
}

\author{
Наталья Владимировна Уфимцева \\ Институт языкознания РАН, г. Москва, Россия
}

\section{Ольга Вениаминовна Балясникова}

Институт языкознания РАН, г. Москва, Россия; Первый Московский государственный медицинский университет им. И.М. Сеченова, г. Москва, Россия

Аннотация. В статье охарактеризованы возможности лексикографического представления языковой картины мира с опорой на положения концепции московской психолингвистической школы о системности картины мира в сознании носителя культуры / языка, о значении как идеальной форме существования предметного мира, о свободном ассоциативном эксперименте, проводимом с большим количеством испытуемых - носителей национального языка / культуры, как одном из оптимальных методов фиксации знаний, стоящих за словом в обыденном сознании носителя языка / культуры.

Показано, что фиксируемая в ассоциативных словарях ассоциативно-вербальная сеть, построенная по данным массовых ассоциативных экспериментов, отражает системность связей ее элементов - слов, каждое из которых в свою очередь имеет свое значение со своей системностью. Сравнение фрагментов языковой картины мира - компонентов этой модели - позволяет сделать выводы о несовпадении не просто значений (знаний, стоящих за словами) компонентов, но и их системности. Ассоциативно-вербальная сеть как целостная модель языковой картины мира способна отражать элементы в системе, на микро- и макроуровнях, что позволяет судить не только о значении, но и о значимости каждого ее элемента.

С появлением ассоциативной лексикографии стало возможным смоделировать целостную картину мира «наивного» носителя языка / культуры, наблюдать реальное взаимодействие и взаимозависимость значения и значимости отдельного слова как в пределах всей ассоциативно-вербальной сети, так и в рамках отдельного ассоциативного поля. Материалы массовых ассоциативных экспериментов отражают реальное состояние обыденного сознания носителя определенного языка / культуры и могут использоваться как для анализа его синхронного состояния, так и для фиксации происходящих в нем изменений в диахронии при наличии нескольких временных срезов, указывающих на изменения в структуре ассоциативно-вербальной сети и в содержании знаний, стоящих за словом-стимулом, в зависимости от изменений, происходящих в социуме.

Ключевые слова: картина мира, языковая картина мира, категория деятельности, ассоциативно-вербальная сеть, ассоциативный словарь-тезаурус, значение, значимость.

Цитирование. Уфимцева Н. В., Балясникова О. В. Языковая картина мира и ассоциативная лексикография // Вестник Волгоградского государственного университета. Серия 2, Языкознание. - 2019. - Т. 18, № 1. C. 6-22. - DOI: https://doi.org/10.15688/jvolsu2.2019.1.1

\section{Введение}

Понятие картины мира является междисциплинарным. Оно было осмыслено в рамках точных наук (физическая картина мира у Г. Герца и М. Планка), философии (концепции И.Г. Гердера и Л. Витгенштейна) и лингвистики (идеи В. фон Гумбольдта, Л. Вайсгербера) применительно к задачам, которые и вызвали необходимость появления этого понятия. Возникнув на рубеже XIX-XX вв., оно толковалось как отражение объективного мира в категориях и формах, доступных человеческому сознанию.
Г. Герц говорил о физической картине мира как о совокупности внутренних образов, или символов, внешних предметов, из которых логическим путем можно получать сведения относительно поведения этих предметов. Собственно, речь шла о научной картине мира, формирование которой обусловлено необходимостью изучения закономерностей реального мира и предвидения будущего опыта; для чего и создаются указанные образы или символы [Герц, 1959]. Образами Г. Герц называл наши представления о вещах (между теми и другими возможны несовпадения) [Герц, 1959, с. 14] и предлагал гипотезу, «которую не было 
принято вводить в элементы механики»: «Мы убеждаемся, что многообразие действительного мира должно быть бо́льшим, чем многообразие мира, непосредственно доступного нашим чувствам. Если мы хотим получить законченную, замкнутую в себе, закономерную картину мира, то мы должны допускать за вещами, которые мы видим, еще другие, невидимые вещи, и искать за пределами наших чувств еще скрытые факторы...» [Герц, 1959, с. 41]. В целом научная (физическая) картина мира, в отличие от практической, представляла собой модель мира реального, объективную и свободную «от индивидуальности творческого ума» [Планк, 1975, с. 632].

Способность отражать действительность предполагает отделение человеком себя от окружающего мира и соотнесение себя с тем, что является по отношению к человеку внешним, объективным [Рубинштейн, 1998]. Реальный мир может быть представлен в виде модели, упрощающей его, как и всякая модель; в этом смысле собственно «мир»- результат переработки сознанием информации о среде и о самом человеке [Топоров, 1992]. Рассуждая о понятии картины мира, М. Хайдеггер писал: «Картина мира, сущностно понятая, означает, таким образом, не картину, изображающую мир, а мир, понятый как картина... Сущее в целом берется теперь так, что оно только тогда становится сущим, когда поставлено представляющим и устанавливающим его человеком. Где дело доходит до картины мира, там выносится кардинальное решение относительно сущего в целом. Бытие сущего ищут и находят в представлении сущего» [Хайдеггер, 1986, с. 103]. Сознание человека оперирует, по сути, моделью действительности, расчленяющей ее на фрагменты определенным образом в каждом языке, и полученная картина мира при сходстве явлений реальности различна в тех системах, в которых она представлена.

Одной из таких форм «представления» реального является система естественного языка.

Будучи важнейшим средством коммуникации, язык способен оказывать влияние на речевое и неречевое поведение людей и на их отношения в различных сферах межличностных и межгрупповых контактов (см., напри- мep: [Azab, Clark, 2017; Lau, Lee, 2018; Rosa, 2016], а также определять их отношение к нему самому. «В ходе осознания общего родного языка, - писал Л. Вайсгербер, - вырастает чувство сплоченности, возрастает желание держаться вместе и действовать тоже как единое целое. И наоборот, сущность языка проясняет, почему языковые конфликты повсеместно принимают столь ожесточенную форму там, где попытки отчуждения народа от его родного языка наталкиваются на здоровое народное сознание... Именно там, где народ видит свои важнейшие жизненные ценности, он прилагает все усилия к сохранению и культивированию родного языка... Наши наблюдения за языковыми содержаниями, за внутренней формой языка как раз таки показывают нам, почему язык является самой прочной и самой основной опорой народного самоутверждения, которое мы вообще признали характеристикой и связующей силой народа» [Вайсгербер, 2009, с. 132-133].

\section{Языковая картина мира}

Языковая картина мира в самом общем ее понимании отражает представление реального мира в системе понятий и категорий языка. По Л. Вайсгерберу, язык сообразно со своей внутренней формой передает своим носителям мировидение, отличное от мировидения, передаваемого другими языками. Признавая это как самую выдающуюся возможность, которой располагает язык, можно получить определение его как формы общественного познания [Вайсгербеp, 2009, с. 119].

Освоение мира предполагает его одновременное осмысление, а процесс отражения действительности сознанием происходит одновременно с процессами речепроизводства [Колшанский, 1990]. Таким образом, «картина мира, отображенная в сознании человека, есть вторичное существование объективного мира, закрепленное и реализованное в своеобразной материальной форме. Этой материальной формой является язык» [Колшанский, 1990, с. 15]. Языковые процессы (такие, например, как номинация) неразрывно связаны с процессами выделения объектов из окружающего мира и их осмысления. 
Отсюда интерес к данным полевых исследований и обсуждение тождественности картины мира, существующей в сознании носителя языка, ее языковому выражению и соответствия последнего фрагменту действительности [Караулов, 1976]. В этом отношении важны и межъязыковые сравнения, в которых выявляются несовпадения концептуального плана (см., например: [Денисенко, 2006]). Обоснование действия языковых механизмов применительно к человеческому сознанию нашло свое отражение в когнитивной теории метафоры и в других формах «культурных концептуализаций» [Sharifian, 2017].

Взаимосвязь категорий язык, сознание и культура становится все более очевидной и в том или ином виде эксплицируется во многих исследованиях, посвященных особенностям отражения реального мира человеческим сознанием. Ф. Боас полагал, что в основе языка лежат неосознаваемые категории, воздействующие на формы мышления и заставляющие видеть мир определенным образом, поэтому «...абсолютные системы явлений - как комплексные, так и феноменов культуры невозможны. Они всегда будут отражением нашей собственной культуры» [Боас, 1997, c. 535]. Факты языка, составляющие часть повседневного опыта человека, поэтому не осознаются и не сравниваются с другими, поскольку целый ряд объективно существующих, но не имеющих применения в повседневной деятельности явлений игнорируется человеком. Языковая система, хранящаяся в сознании носителей языка, упорядочивает поток впечатлений от внешнего мира; расчленение мира, его отражение в понятиях и распределение значений - результат «соглашения», закрепленного в системе моделей определенного языка [Уорф, 1960]. Известная теория лингвистической относительности получает современное осмысление в рамках лингвокультурологии: обсуждается связь языка с культурным опытом его носителей, влияние моделей языка на мышление [Keith, 2010; Lucy, 2015]. Кроме того, высказываются суждения о семиотическом повороте в науках об обществе и культуре, в котором особая роль принадлежит лингвистике [Семиотический поворот в социально-гуманитарном познании..., 2018]. Заметим, что в качестве предпосылок семиоти- ки культуры указаны: 1) различение между символическим и несимволическим в бытии человека, 2) различие (семиотический барьер) между культурой, к которой принадлежит исследователь, и культурой, которую он изучает, 3) интерес к значению явлений в контексте семиотики культуры [Демин, 2018].

Базисные представления о языке как мировидении и картине мира трактуются в рамках гипотезы-теории В. фон Гумбольдта о языке как деятельности [Постовалова, 2017, с. 67]. «“Картина мира”, как и ее процессуальный аналог “мировидение”, - пишет В.И. Постовалова, - относятся к числу базисных понятий учения о человеке как homo symbolcus'e. По этому учению, сущностной характеристикой человека является наличие у него особых символических структур - языка, мифологии, религии, искусства, науки, запечатлевающих систему его миропредставлений и выступающих в роли регуляторов его жизнедеятельности. С помощью таких опосредствующих символических структур человек формирует себе образ (картину, эскиз, модель мира) как основу своей жизнедеятельности и культуры» [Постовалова, 2017, с. 68]. Изучению картины мира как антропологического феномена предшествовало философское исследование мироощущения человека, а также разработка представлений о научной картине (научных картинах) мира [Постовалова, 2017, с. 79].

Становится очевидным, что отражение картины мира в языке / языковая картина мира (именно языковой аспект картины мира интересует лингвистику) может интерпретироваться по-разному. На первый план в этой интерпретации выходит содержательный аспект языковых явлений - таким образом, реконструкция языковой картины мира становится одной из задач лингвистической семантики: «Поскольку языковая модель мира закреплена и выражена в первую очередь в языке, в его лексике и значимых грамматических категориях, то метод описания данного объекта - это семантический анализ лексических и грамматических значений того или иного конкретного языка» [Корнилов, 2003, с. 12]. Эти категории могли далее изучаться на конкретном языковом материале. Отечественная семантика занималась, в частности, исследованием русской языковой картины мира, концеп- 
тосферы (работы Ю.Д. Апресяна, Н.Д. Арутюновой, Ю.С. Степанова, Анны А. Зализняк, Е.В. Урысон, А.Д. Шмелева и др.).

В этом отношении переосмыслению подвергаются и понятие семантики, и ее задачи. Так, в работе «Язык как идеология и язык как техника» В.И. Абаев говорит о том, что существует «семантика изолированных, технических значений - техническая семантика и семантика генезиса и взаимосвязи значений - идеологическая семантика... Одно и то же понятие «богатство» выражено в трех различных языках: русском, осетинском и немецком, - тремя различными способами. В русском оно связано с «богом», в осетинском с «днем», «светом» (bond әn от bon 'день'), в немецком - с «царской властью» (reich). Техническая семантика этих трех слов - одна и та же. Семантика идеологическая - разная. Каждое [слово] говорит об особом мировоззрении и об особых условиях общественного существования в эпоху формирования этих слов» [Абаев, 2006, с. 28]. Далее на примере семантики слова солнце автор выделяет так называемое «ядро» (представление о солнце как о светиле) - устойчивое, суммирующее эмпирический опыт многих людей, объективное, технически-эмпирическое, - и «оболочку», то есть субъективные, так называемые идеологические, настроения и ассоциации (представления о солнце как о божестве), которые обусловлены сознанием и опытом людей конкретной эпохи и среды. Ядро, согласно В.И. Абаеву, имеет источник в предметной деятельности и является материалом научного познания, оболочка берет начало в общественной идеологии и является материалом для мифологических, религиозных, метафизических, поэтических построений [Абаев, 2006, с. 30].

Попытки осмысления языковой картины мира продолжались и продолжаются на уровне терминологии и понятийного аппарата и на уровне изучения отдельных ее фрагментов, как правило концептов, а также на уровне конкретных форм межкультурного взаимодействия [Богачев, 1998; Горобец, 2008; Крапотина, 2017; Лебедева, 2008; Магомедова, 2008; Региональная картина мира..., 2017; Сухарева, 2012; Хижняк, 2016; Чуликов, 2010; Чупрына, 2011; Baydak, Scharioth, Ilyashenko 2015;
Bekova, 2013; Chakyroglu, Suiyerkul, 2014; Khorechko et al., 2015; Strotkina, Gillespie, 2014 и др.]. Исследователи обращаются к анализу национально-культурной специфики речевого и неречевого поведения, которая формируется в совместной деятельности носителей языка / культуры, что представляется некоторой презумпцией (см., например: [Taylor, 2013]).

В настоящее время можно выделить два основных направления в исследовании языковой картины мира. Одно из них связано с изучением феномена как такового, точнее - с изучением фрагмента языковой картины мира по данным языка, прежде всего по его лексике (особое место здесь занимает область фразеологии: [Золотых, 2007; Лескина, 2009; Юздова, 2009]). Речь идет о разных способах языковой концептуализации мира, и картина мира понимается как его модель [Воротников, 2006, c. 90; Зализняк, Левонтина, Шмелев, 2005; Урысон, 2003, с. 9], таким образом, предполагается ее облигаторность, что не является новым в рассуждении о связях языка и культуры (ср., например: [Верещагин, Костомаров, 1973]). Другое направление связано с исследованием фактов собственно языка, при этом языковая картина мира принимается по умолчанию как интерпретационное поле [Альмяшова, Монастырская, 2016].

Одной из современных тенденций изучения языковой картины мира в связи с национальной культурой становится обращение исследователей к культурным ценностям и к формам их отражения в национальном языке. Ценности понимаются как высшие ориентиры поведения, отраженные в языковом сознании и коммуникативном поведении [Ценностная картина мира..., 2016]. Эта тенденция определенно детерминирована проблемами, обусловленными происходящими в мире процессами, в том числе языковыми (см., в частности: [Балясникова, 2015]). Фрагмент языковой картины мира представлен в разнообразных концептах на разнообразном же языковом материале: в «китайской фразеологической картине мира», «в лингвокультурах», «в русском языковом сознании» и т. п. Научный антропоцентризм инициирует также изучение речевой деятельности отдельной личности; отсюда конкретные интерпретации понятия картины мира, например как «ментально-язы- 
ковой детерминанты» [Шпильная, 2017], включенной в речемыслительную деятельность личности, в частности, в ее текстовую деятельность.

\section{Категория деятельности и языковая картина мира}

Первым лингвистом, положившим в основу своей концепции языка принцип деятельности, был В. фон Гумбольдт [Постовалова, 2017]. Рассмотрение языка в его диалектике - как процесса, как готовой данности, как части психической деятельности человека и как общественного явления - обусловливает представление о речевой деятельности, понимание языка как связующего звена между социумом и человеком. «Язык живет и творит в национальности, и тайна его сущности в полноте являет себя преимущественно в том, что он выходит из внешне беспорядочной массы индивидуальностей, среди которых ни одной нет нужды выделяться именно порознь... Язык можно поэтому мыслить только в связи с народом, и каким бы простым и известным ни казался этот принцип, впоследствии скоро обнаружится, сколь богат он выводами и сколь часто он выпускался из виду» [Гумбольдт, 2018 , с. 300]. Поскольку категория деятельности характеризует мир человека, закономерно ее использование именно в гуманитарном знании [Постовалова, 2014].

Категория речевой деятельности, осуществляемой человеком наряду с другими своими деятельностями в мире, устанавливает и объясняет отмеченную нами выше взаимосвязь понятий языка, сознания и культуры. С собственно языковыми факторами оказываются связанными другие: культурная традиция, социальные ситуации и функции общения, особенности протекания и опосредования психических процессов и различных видов деятельности - положения об этом были сформулированы в рамках психологии и социолингвистики. Поскольку сознание человека всегда этнически обусловлено (А.А. Леонтьев), очевидно, что изменение или навязывание того или иного знака не просто механическое включение его в языковую систему, но изменение картины мира, и форсирование этого процесса имеет серьезные последствия не только для языка, имеющего собственные тенденции развития, но и для людей, чья картина мира изменяется вопреки этим естественным процессам [Погорелая, 2006]. Существующая в современном мире тенденция к культурной и языковой унификации, обусловленная процессами глобализации, неизбежна и порождает противоположное ей стремление народов к сохранению культурной и языковой идентичности и национального языка как одной из основных ценностей культуры и выразителей картины мира [Никитенко, 2010]. Языковое многообразие не только вызывает сложности во взаимопонимании между носителями различных языков и затрудняет социализацию мигрантов, но и может приводить к внутреннему дискомфорту коммуникантов в бытовом общении, к непониманию ценностей, норм, привычек представителей другой культуры. Социальные, культурные и языковые факторы подтверждают свою взаимосвязь [Faizah, 2016].

В отечественной психолингвистике понятие картины мира традиционно рассматривается с позиций деятельностного подхода, связанного с именем А.Н. Леонтьева и психологической школой Л.С. Выготского, и соотносится с понятием «образ мира» в отечественной (советской) психологии. Лингвистический подход предполагает трактовку последнего как результата комплексного воздействия опосредующих символических структур [Роль человеческого фактора в языке..., 1988], психолингвистический подход - как отображения в психике человека предметного мира, опосредованного предметными значениями и поддающегося сознательной рефлексии. Приобретаемые человеком знания отражают процесс восприятия действительности человеком в процессе деятельности, предполагающей взаимодействие с ее объектами. Структура деятельности признается универсальной, в то время как способы совершения действий зависят от естественных природных условий жизни, предметов, создаваемых самими людьми в процессе деятельности, и норм социального поведения. В процессе совершения разнообразных деятельностей (а способ их совершения обусловлен системой установок и правил национальной культуры) формируются знания об окружающем мире. Таким образом, каждая культура способствует усвоению 
индивидом определенной системы знаний и способов ее организации. В системе культурно выработанных значений, соответствующих разным социальным феноменам, выделяются понятийные компоненты национальной культуры данного исторического этапа развития, социальные установки, ценности и социальные роли, то есть образ жизни народа в конкретное историческое время, наконец определенные стереотипы действий [Леонтьев, 1981].

Изучение межкультурных различий, находящих отражение в языке и сознании, становится одним из наиболее актуальных направлений, разрабатываемых в настоящее время в отечественной психолингвистике. Взаимосвязь культуры, национального самосознания и языка проявляется в базовых смыслах (понятиях) каждой культуры. Психолингвистическая интерпретация данных, представленных в языке, позволяет рассматривать последние как репрезентанты особых знаний, стоящих за фактами (знаками) естественного языка. Таким образом, посредством взаимозависимых базовых понятий - «культура», «деятельность» и «языковое сознание» - характеризуется отражение этой деятельности в ее обусловленности системой культурных регуляторов и выражение этих отношений в коммуникации единицами и категориями языка.

В рамках концепции московской психолингвистической школы, базирующейся на положениях теории речевой деятельности, были приняты следующие положения для изучения языковой картины мира:

1. Каждая культура задает свою системность картины мира, что обусловливает несходство картин мира в сознании носителей различных языков.

2. Язык как деятельностная структура представляет собой результат отображения в знаковой форме социокультурной реальности, элементы которой имеют определенную значимость именно в системе конкретной культуры. Следовательно, изучение значения как знания определяет конкретное направление исследования картины мира или ее фрагмента. Именно значения как идеальная форма существования предметного мира лежат в основе механизма передачи знаний и управляют внутренней и внешней деятельностью людей, и именно значения представляют собой идеальную форму существования предметного мира, его свойств, связей и отношений, раскрытых совокупной общественной практикой (А.Н. Леонтьев).

3. Оптимальным методом для обнаружения и изучения этих значений / знаний являются психолингвистический эксперимент, при интерпретации данных которого в качестве «невидимого» контекста языковой единицы предполагается весь речевой и неречевой опыт носителя языка.

\section{Отражение картины мира в лексикографии}

В процессе анализа фактов лишь одного языка исследователям картины мира приходится много внимания уделять теоретическим проблемам ее отражения в языке. В случае, если в исследовании задействовано два языка или более, возможно сравнение фрагментов языковой картины мира. Несмотря на трудоемкость последнего, общенаучный метод сравнения делает явным несходство языковых картин мира у носителей разных языков.

В 70-е гг., по мнению Ю.Н. Караулова, существовало два подхода к слову, отразившихся в лексикографической практике того времени: это трактовка слова как самостоятельной сущности, с одной стороны, и как сущности, значение / содержание которой «растворено» в контексте - с другой [Караулов, 1976]. К этому времени складываются предпосылки для создания идеологического / идеографического словарей - семантически упорядоченных словарей-тезаурусов. «Можно думать, - пишет Ю.Н. Караулов, - что словарь языка, существующий в сознании пользователя языков, представляет собой тоже определенную манифестацию лексики, хотя способ его существования отличается от первого. Такой словарь не является уже, очевидно, списком слов, закрытым набором знаков, а упорядочен иным образом» [Караулов, 1976, c. 69-70].

Позже при составлении словарей исследователи будут стремиться отразить языковую картину мира, с одной стороны, и опереться на известные и выработанные в лексикографической практике принципы - с другой, что 
найдет отражение, например, в НОСС, где каждая словарная статья представляет собой описание фрагмента языковой картины мира [Урысон, 2003]. В Предисловии к словарю среди принципов, на которых он основан, указаны идеографичность и ориентация на отражение языковой, или «наивной», картины мира; поясняется, что делаются попытки увидеть за синонимическими рядами «определенный фрагмент некоего общего взгляда на мир, присущего данному языку», и предполагается, что «это особое мировидение может отличаться как от научной картины мира, так и, возможно, от способов видеть мир, присущих другим языкам» [Апресян, 2004, с. IX]. Этот подход отражает более высокий уровень лингвистической семантики 90-х гг., чем объясняется повышенный интерес к языковой картине мира и системным явлениям в лексике [Апресян, 2004].

К настоящему времени в описании языковой картины мира представлены отмеченные нами выше взаимосвязи языка, сознания и мира культурных предметов (реалий). «Описание мира духовной культуры предполагает рассмотрение в тесной взаимосвязи трех ее важнейших составляющих. Это, во-первых, реалий (вещей, жизненных ситуаций, мифологем), значимых для данной культуры и концептуализируемых в ее пространстве. Во-вторых, концептов (понятий и образов) как их смысловых отображений, образующих концептосферы миропредставлений данной культуры. И, наконец, в-третьих, ключевых слов языка культуры, воплощающих эти концепты» [Постовалова, 2017, с. 79-80]. Картина мира может быть изучена как модель в виде языковой репрезентации ключевых понятий культуры. Последние могут быть названы константами, или концептами, и обозначаются словами национального языка (см., например: [Карасик, 2002; Степанов, 1997]). Результаты изучения концептов представлены в обширной научной литературе, на рассмотрении которой мы не будем здесь останавливаться.

Исследуемые в рамках методологического подхода Московской психолингвистической школы ассоциативные значения слов национального языка трактуются как образы языкового сознания, отражающие знания о мире носителя языка / культуры.
Еще в 70-е гг. прошлого века А.А. Леонтьев, анализируя различные подходы к описанию значения, приходит к пониманию психолингвистикой значения слова как «субъективного содержания знакового образа» и отмечает, что оно у разных индивидов всегда совпадает «по отнесенности к данному конкретному предмету», но может отличаться как «по отнесенности к социальной действительности (по идеальному содержанию)», так и «по субъективному содержанию» [Леонтьев, 1976, c. 47]. Язык, по А.А. Леонтьеву, отображает социокультурную реальность; система смысловых единиц, конституирующая образ мира носителей языка / культуры, является ориентировочной основой для деятельности человека. Образ мира построен из предметных значений, система которых должна быть предметом изучения для антропоцентрической лингвистики [Леонтьев, 1996] (подробно об этом см.: [Уфимцева, 2016]).

Под языковым сознанием понимается сознание индивида, имеющее дело со значениями как социальными образованиями. Для наблюдения и исследования оно становится доступным через опосредование знаком языка в виде отдельного слова, словосочетания, ассоциативного поля, текста. Таким образом могут быть изучены сами знания, полученные в процессе социализации в рамках определенной культуры, выраженные с помощью языка - то есть языковая картина мира носителей национального языка / культуры [Уфимцева, 2016; Debrenne, Ufimtseva, 2011].

Ассоциативные данные, полученные в результате проведения эксперимента с большим количеством испытуемых - носителей национальных языков / культур, обобщаются с применением методов количественного (статистического) и качественного анализа. Первый позволяет выявить частотность выделяемого компонента ассоциативного значения и сравнить частотность сходных компонентов в содержании стимульных слов. Второй позволяет описать и смоделировать содержание ассоциативного поля по определенным критериям. Полученный материал подвергается также сравнительно-сопоставительному анализу, который помогает выявить ранг исследуемого фрагмента языкового сознания носителей той или иной культуры, то есть его зна- 
чимость (по Ф. де Соссюру, см. об этом: [Уфимцева, 2013]), а не только описать значение этого фрагмента.

Результаты такого «системного» подхода к значению слова представлены в виде уже известных научному сообществу словарей (РАС, изданного в нулевые годы) и новых ассоциативных словарей (ЕВРАС, СИБАС, изданных в 2010-е годы), а также построенных на этих данных ассоциативно-вербальных сетей.

\section{Принципы ассоциативной лексикографии}

Можно считать, что начало ассоциативной лексикографии положили вербальные ассоциативные нормы, установленные в опубликованной в 1910 г. работе Кент и Розановым [Kent, Rosanoff, 1910]. Вслед за ней в США, а потом и в других странах стали появляться исследования, в которых использовался один и тот же список из ста стимульных слов (подробное описание всех существующих ассоциативных словарей и баз данных см. в [Еленевская, Овчинникова, 2016]). В отечественной психолингвистике первым опытом в этой области стал «Словарь ассоциативных норм русского языка» под ред. А.А. Леонтьева (САНРЯ).

Для описания языковой картины мира (обыденного языкового сознания как целого) наибольший интерес представляют так называемые ассоциативные тезаурусы. Существуют два ассоциативных тезауруса: Английский ассоциативный тезаурус (EAT) и Русский ассоциативный словарь (РАС).

Ассоциативно-вербальная сеть, построенная по материалам ассоциативного тезауруса, дает четкое представление об устройстве языкового сознания / обыденного образа мира и может рассматривается в качестве модели языковой картины мира (языкового сознания). Эта модель отражает весь предыдущий речевой и неречевой опыт носителя языка / культуры и имеет системно-целостный характер, поскольку организована с точки зрения значимости входящих в нее элементов. Для анализа этого аспекта модели применяется понятие ядра и периферии языкового сознания.
Указанная модель может быть создана на материале любого языка при наличии достаточно большого количества данных, полученных в ассоциативных экспериментах. Ее важнейшая особенность состоит в том, что она не конструируется искусственно, а «выводится» из материала, в котором содержится имплицитно. Таким образом, модель отражает структуру, объективно присущую языковой картине мира носителя языка / культуры, поскольку, как мы указывали выше, мир презентирован отдельному человеку через систему предметных значений, «наложенных» на восприятие этого мира, причем каждой культуре свойственна своя система организации элементов опыта. Эти элементы не всегда являются уникальными для той или иной культуры; уникален способ их организации структура.

Организующим для целой модели и для каждого ее фрагмента является принцип значимости, провозглашенный Ф. де Соссюром. Каждый элемент ассоциативно-вербальной сети имеет и значение (знания, которые входят в ассоциативное поле слова-стимула) и значимость (ранг в ассоциативно-вербальной сети) одновременно. Таким образом, исследования языковой картины мира носителей языка / культуры, осуществляемые в рамках деятельностного подхода к языку, имеют в отечественной психолингвистике ряд особенностей, которые нашли отражение в ассоциативной лексикографии.

Во-первых, психолингвистика занимается изучением не отдельных, изолированных друг от друга концептов, слов, выражений или категорий языка, а системы таковых, используя при этом возможности ассоциативно-вербальной сети. Последняя представляет собой модель обыденного образа мира (языкового сознания) носителей языка / культуры, позволяющую увидеть не только значение каждого ее элемента, но исследовать сам элемент в его системности и значимости. Ассоциативно-вербальная сеть (АВС) представляет именно целостную модель языковой картины мира и, как необходимо для любой модели, имеет свой объем и особую структуру; АВС отражает системность связей элементов, их взаимообусловленность (то есть системность знаний о мире) так, как позволяет данная модель. 
Во-вторых, каждый элемент модели слово - имеет свое (ассоциативное) значение, соотносимое с психологическим понятием «образ сознания». Ассоциативное значение каждого слова - это также своего рода микромодель, включающая ядро (частотные связи слов, общие для носителей данного языка / культуры) и периферию (нечастотные или единичные, уникальные связи слов). Ядро, отражающее общие для носителей языка / культуры знания, имеет устойчивый во времени характер; периферия изменяется под воздействием происходящих в конкретный исторический период социальных и политических процессов. Отметим (см., например: [Балясникова и др., 2018; Региональное языковое сознание..., 2017]), что при межьязыковом /межкультурном сопоставлении содержания знаний можно говорить о сходстве / различии как отдельных знаний, стоящих за псевдоэквивалентными словами (системе знаний, отраженной в структуре ассоциативного поля), так и о сходстве / различии культур как целого - образа мира, «взятого» в его системности.

\section{Выводы}

В научных рассуждениях о природе картины мира и способах ее представления неизбежно затрагивался вопрос о роли сознания в этом процессе и признание того факта, что картина, которая получается в результате восприятия объективного мира человеком, его сознанием, имеет существенные отличия от объективной реальности. Языковая картина мира - результат преломления этой реальности в языковых категориях и формах, что приводит исследователя к необходимости определить для себя, к чему именно (к сознанию или к чему-либо иному?) он получает доступ, анализируя эти формы и категории.

Рассуждая о двух взаимоисключающих подходах к языку и сознанию, существующих в философской, психологической и лингвистической литературе, А.А. Леонтьев, писал: «Согласно одному из них, единицей сознания, тем, в чем и при помощи чего существует сознание, является система вербальных, словесных значений и обслуживающих эти значения разноуровневых коммуникативных средств. Проще: система языковых знаков. Отсюда все нео- гумбольдтианство, включая теорию лингвистической относительности; отсюда лингвистическая философия, общая семантика и другие неопозитивистские трактовки языка. Согласно другому подходу единицей сознания является предметное значение, а язык в этом случае понимается как система значений, могущих актуализироваться и в вербальной форме» [Леонтьев, 1993, с. 16-17]. Очевидно, что лингвистические работы по исследованию языковой картины мира, с презумпцией связи сознания и вербального значения, оказываются ближе к первому подходу, обозначенному А.А. Леонтьевым. Более того, лингвист изучает, как правило, им же отбираемые, нередко изолированные друг от друга единицы, в значениях которых и пытается обнаружить «языковую картину мира» обычного носителя языка, опираясь на свою интуицию, языковое чутье. Здесь, скорее всего, можно говорить о языковой картине мира самого исследователя и о том, что успех описания «наивной» языковой картины мира будет определяться в числе прочих факторов тем, какие источники данных будут в его распоряжении. Очевидно, что для приближения к описанию «реальности», стоящей за значениями и категориями языка, необходимо, во-первых, иметь о них определенное представление (что именно может быть изучено, в какой мере объективно то, что доступно наблюдению и изучению), а во-вторых, выбрать методы, позволяющие если не исключить, то хотя бы уменьшить степень субъективности, связанную с «индивидуальностью творческого ума» исследователя.

Методы, которые применяет отечественная психолингвистика, позволяют получить данные, отражающие коллективный опыт носителей языка. С появлением ассоциативной лексикографии оказалось возможным впервые смоделировать целостную картину мира «наивного» носителя языка / культуры, наблюдать реальное взаимодействие и взаимозависимость значения и значимости отдельного слова как в пределах всей ассоциативно-вербальной сети, так и в рамках отдельного ассоциативного поля. Материалы массовых ассоциативных экспериментов отражают реальное состояние обыденного сознания носителя определенного языка / культуры и мо- 
гут использоваться как для анализа его синхронного состояния, так и для фиксации происходящих в нем изменений в диахронии при наличии нескольких временных срезов, указывающих на изменения в структуре ассоциативно-вербальной сети и в содержании знаний, стоящих за словом-стимулом, в зависимости от изменений, происходящих в социуме (см., например, САНРЯ, РАС и ЕВРАС).

\section{СПИСОК ЛИТЕРАТУРЫ}

Абаев В. И., 2006. Статьи по теории и истории языкознания. М. : Наука. 150 с.

Альмяшова Л. В., Монастырская Е. А., 2016. Современные лингвистические исследования: языковая актуализация картины мира. Кемерово : КемТИПП. 105 с.

Апресян Ю. Д., 2004. Предисловие // Новый объяснительный словарь синонимов русского языка / под общ. руков. акад. Ю. Д. Апресяна. 2-е изд., испр. и доп. М. ; Вена : Языки славянской культуры : Венский славистический альманах. C. VIII-XI. URL: http://www.lrc-lib.ru/ ruslang/noss/intro.pdf

Балясникова О. В., 2015. Язык как инструмент конфликта и конфликтогенные языковые процессы в современном мире: Славянский ареал. (Обзор) // Актуальные проблемы Европы. № 1. C. $194-213$.

Балясникова О. В., Уфимцева Н. В., Черкасова Г. А., Чулкина Н. Л., 2018. Языковое сознание: региональный аспект // Вестник Российского университета дружбы народов. Серия: Лингвистика. Т. 22, № 2. С. 232-250. DOI: 10.22363/ 2312-9182-2018-22-2-232-250.

Боас Ф., 1997. История и наука в антропологии // Антология исследований культуры. СПб. : Университетская книга. С. 528-535.

Богачев Р. Н., 2008. Фактор структуры языка в анализе языковой картины мира // Научная мысль Кавказа. № 3. С. 70-74.

Вайсгербер Й. Л., 2009. Родной язык и формирование духа. Изд. 3-е. М. : ЛИБРОКОМ. 232 с.

Верещагин Е. М., Костомаров В. Г., 1973. Язык и культура. Лингвострановедение в преподавании русского языка как иностранного. М. : Изд-во Моск. ун-та. 233 с.

Воротников Ю. Л., 2006. «Языковая картина мира»: трактовка понятия // Знание. Понимание. Умение. № 2. С. 88-90.

Герц Г., 1959. Принципы механики, изложенные в новой связи. М. : Изд-во Акад. наук СССР. 386 c.
Горобец А. Ф., 2008. Языковая и культурная картины мира: современный подход к проблеме // Культурная жизнь Юга России. № 1 (26). С. 11-13.

Гумбольдт В. фон, 2018. Концепция общего языкознания: цели, содержание, структура. Избранные переводы. М. : ЛЕНАРД. 504 с.

Демин И. В., 2018. Семиотический поворот в науках о культуре // Семиотический поворот в социально-гуманитарном познании: истоки, предпосылки, культурный контекст : коллектив. моногр. / отв. ред. И. В. Демин. Самара : Самар. гуманит. акад. С. 5-17.

Денисенко В. Н., 2006. Метод семантического поля и языковая картина мира (Наименование изменения в русском языке) // Вестник Российского университета дружбы народов. Серия: Лингвистика. № 8. С. 5-16.

Еленевская М. Н., Овчинникова И. Г., 2016. Хранение и описание вербальных ассоциаций: словари и тезаурусы // Вопросы психолингвистики. № 3 (29). С. 69-92.

Зализняк Анна А., Левонтина И. Б., Шмелев А. Д., 2005. Ключевые идеи русской языковой картины мира. М. : Языки славянской культуры. $540 \mathrm{c}$.

Золотых Л. Г., 2007. Когнитивно-дискурсивные основы фразеологической семантики. Астрахань : Астраханский университет. 265 с.

Карасик В. И., 2002. Языковой круг: личность, концепты, дискурс. Волгоград : Перемена. $477 \mathrm{c}$.

Караулов Ю. Н., 1976. Общая и русская идеография. М. : Наука. 355 с.

Колшанский Г. В., 1990. Объективная картина мира в познании и в языке. М. : Наука. 108 с.

Корнилов О. А., 2003. Языковые картины мира как производные национальных менталитетов. Изд. 2-е. М. : ЧеРо. 349 с.

Крапотина Т. Г., 2017. От картины мира реальной к картине мира метафорической: ассоциативно-образный потенциал фразеологизма. М. : ACOУ. 158 c.

Лебедева Л. В., 2008. Современные лингвистические подходы к изучению языковой картины мира // Вопросы культурологии. № 5. С. 6-8.

Леонтьев А. А., 1976. Психолингвистический аспект языкового значения // Принципы и методы семантических исследований. М. : Наука. C. 46-73.

Леонтьев А. А., 1993. Языковое сознание и образ мира // Язык и сознание: парадоксальная рациональность. М. : Ин-т языкознания РАН. C. $16-21$.

Леонтьев А. А., 1996. Язык не должен быть «чужим» // Этнопсихолингвистические аспекты преподавания иностранных языков. М. : ММА 
им. И.М. Сеченова - Ин-т языкознания РАН. C. $41-47$.

Леонтьев А. Н., 1981. Проблемы развития психики. М. : МГУ. 584 c.

Лескина С. В., 2009. Русские и английские фразеологизмы пейоративной семантики как отражение языковой картины мира. Челябинск : Атоксо, 2009. $148 \mathrm{c}$.

Магомедова Д. М., 2008. Современная трактовка понятия «языковая картина мира» // Известия Дагестанского государственного педагогического университета. Общественные и гуманитарные науки. № 3 (4). С. 76-79.

Никитенко 3. Н., 2010. Школьное образование в Европе: Современные тенденции языковой политики. URL: https://docviewer.yandex.ru/ ?url=ya-serp $\% 3 \mathrm{~A} \% 2 \mathrm{~F} \% 2 \mathrm{Fteacher} 1$. ucoz.com $\%$ $2 \mathrm{~F} \_\mathrm{dd} \% 2 \mathrm{~F} 0 \% 2 \mathrm{~F} 49$.pdf\&c $=558 \mathrm{af58188c4}$ (дата обращения: 23. 06. 2015).

Планк М., 1975. Избранные труды. Термодинамика. Теория излучения и квантовая теория. Теория относительности. Статьи и речи. М. : Наука. 788 с.

Погорелая Е. А., 2006. Русская языковая личность в контексте социокультурной динамики постсоветских государств // Глобализация - этнизация: этнокультурные и этноязыковые процессы : в 2 кн. Кн. 2. М. : Наука. С. 360-386.

Постовалова В. И., 2014. Язык как деятельность: Опыт интерпретации концепции Вильгельма фон Гумбольдта / отв. ред. А. А. Леонтьев. Изд. 2-е, испр. и доп. М. : ЛЕНАРД. 256 с.

Постовалова В. И., 2017. Язык и миропонимание: опыт лингвофилософской интерпретации. М. : ЛЕНАРД. 312 c.

Региональная картина мира в языковой концептуализации: динамика культурных смыслов : сб. ст., 2017 / под ред. Л. А. Мардиевой, Т. Ю. Щуклиной. Казань : Изд-во Казан. ун-та. 284 с.

Региональное языковое сознание коми, русских и татар: проблемы взаимовлияния : коллектив. моногр., 2017 / под ред. Н. В. Уфимцевой. М. ; Ярославль : Канцлер. 240 с.

Роль человеческого фактора в языке. Язык и картина мира, 1988 / отв. ред. Б. А. Серебренников. М. : Наука. 216 с.

Рубинштейн С. Л., 1998. Основы общей психологии. СПб. : Питер. 705 с.

Семиотический поворот в социально-гуманитарном познании: истоки, предпосылки, культурный контекст : коллектив. моногр., 2018 / отв. ред. И. В. Демин. Самара : Самар. гуманит. акад. $270 \mathrm{c.}$

Степанов Ю. С., 1997. Константы: Словарь русской культуры. М. : Языки русской культуры. 824 c.
Сухарева Ю. В., 2012. Взаимообусловленность картины мира и языковой картины мира // Вестник Южно-Уральского государственного университета. Серия «Лингвистика». № 2. С. 110-113.

Топоров В. Н., 1992. Модель мира // Мифы, народов мира. Энциклопедия. В 2 т. Т. 2 / гл. ред. С. А. Токарев. М. : Сов. энцикл. С. 161-164.

Уорф Б. Л., 1960. Наука и языкознание // Новое в лингвистике. М. : Изд-во иностр. лит. Вып. 1. C. $169-182$.

Урысон Е. В., 2003. Проблемы исследования языковой картины мира: Аналогия в семантике. М. : Языки славянской культуры. 223 с.

Уфимцева Н. В., 2013. Идеи Ф. де Соссюра в психолингвистическом прочтении // Вопросы психолингвистики. № 17. С. 44-52.

Уфимцева Н. В., 2016. Языковая картина мира: проблема моделирования // Вопросы психолингвистики. № 27. С. 238-249.

Хайдеггер М., 1986. Время картины мира // Новая технократическая волна на Западе. М. : Прогресс. С. 85-118.

Хижняк С. П., 2016. Национальная культура как фактор формирования языковой и концептуальной картин мира (на примере научной картины мира юриспруденции) // Известия Саратовского университета. Новая серия. Серия. Филология. Журналистика. Т. 16, № 2. С. 130-134.

Ценностная картина мира: лингвокультурные аспекты, 2016. Волгоград : Парадигма ; Тяньцзинь : [б. и.]. 306 с.

Чуликов Ю. М., 2010. Сказочная картина мира как фрагмент фольклорной языковой картины мира // Вестник Пятигорского государственного лингвистического университета. № 4. C. 147-151.

Чупрына О. Г., 2011. «Мир» и «родство» в англосаксонской языковой картине мира // Теория и практика общественного развития. № 7. С. 337-339.

Шпильная Н. Н., 2017. Языковая картина мира в структуре речемыслительной деятельности. Изд. 2-е. М. : ЛЕНАРД. 152 c.

Юздова Л. П., 2009. Адвербиальные квалитативные фразеологизмы как средство отражения русской языковой картины мира // Вестник Челябинского государственного университета. № 17 (155). C. 119-123.

Azab C., Clark T., 2017. Speak my language or look like me? - Language and ethnicity in bilingual customer service recovery // Journal of business research. Vol. 72. P. 57-68.

Baydak A. V., Scharioth C., Ilyashenko I. A., 2015. Interaction of Language and Culture in the Process of International Education // Procedia Social and Behavioral Sciences. Vol. 215: 
International Education and Cross-Cultural Communication, Problems and Solutions, (IECC 2015) : International Conference, 9-11 June 2015, Tomsk, Russia : [proceedings]. Tomsk. P. 14-18.

Bekova Z. K., 2013. Ethnic picture of the world and its influence upon the process of adaptation in higher educational establishments $/ / 4^{\text {th }}$ World Conference on Psychology, Counseling and Guidance WCPCG-2013, 24-26 May 2013, Kultur University. Turkey : Istanbul. P. 939-943.

Chakyroglu A. K., Suiyerkul B., 2014. Representation of the concept "Hospitality" in the Kazakh language // Procedia - Social and Behavioral Sciences. Vol. 136. P. 124-128.

Debrenne M., Ufimtseva N., 2011. L'apport des dictionnaires d'associations lexicales aux études de sémantique // Syntaxe et sémantique. № 12. P. 121-137.

Faizah S., 2016. Psycholinguistic determinants of immigrant second language acquisition // Lingua. Vol. 179. P. 24-37.

Keith A., 2010. Vantage Theory and linguistic relativity // Language Sciences. Vol. 32, iss. 2. P. 158-169.

Kent G. H., RosanoffA. J., 1910. A study of association in insanity // American Journal of Insanity. Vol. 67, № 1-2. P. 37-96, 317-390.

Khorechko U. V., Sentsov A. E., Ruchina A. V., Bolsunovskaya L. M., Kazaryan A. A., 2015. The concept of "Tea" in the language picture of the world (Based on Chinese and Russian languages) // Procedia - Social and Behavioral Sciences. The XXVI Annual International Academic Conference, Language and Culture, 27-30 October 2015. Vol. 200. P.215-223.

Lau H. T., Lee R., 2018. Ethnic media advertising effectiveness, influences and implications // Australian Marketing Journal. Vol. 26. P. 216-220.

Lucy J. A., 2015. Sapir-WhorfHypothesis // International Encyclopedia of the Social \& Behavioral Sciences. $2^{\text {nd }}$ Ed. Oxford: Elsevier. P. 903-906.

Rosa J., 2016. Racializing language, regimenting Latinas/os: Chronotope, social tense, and American raciolinguistic futures // Language and Communication. Vol. 46. P. 106-117.

Sharifian F., 2017. Cultural Linguistics and linguistic relativity// Language Sciences. Vol. 59. P. 83-92.

Strotkina T., Gillespie D., 2014. An onomastic approach to the works of A. Ivanov as a reflection of the artistic picture of the world // Procedia - Social and Behavioral Sciences. The XXV Annual international academic conference, Language and culture, 20-22 October 2014. Vol. 154. P. 272-275.

Taylor T. J., 2013. Calibrating the child for language: Meredith Williams on a Wittgensteinian approach to language socialization // Language Sciences. Vol. 40. P. 308-320.

\section{СЛОВАРИ}

$E B P A C-$ У фимцева Н. В., Черкасова Г. А. Русский региональный ассоциативный словарь (Европейская часть России). В 2 т. Т. 1. От стимула к реакции. М. : Моск. междунар. акад., 2018. 544 с. ; Т. 2. От реакции к стимулу. М. : Моск. междунар. акад., 2019. 688 с.

НОСС-Новый объяснительный словарь синонимов русского языка / под общ. рук. акад. Ю. Д. Апресяна. 2-е изд., испр. и доп. М. ; Вена : Языки славянской культуры : Венский славистический альманах, 2004. 1488 c. URL: http://www.lrc-lib.ru/ ruslang/noss/intro.pdf

РАC - Караулов Ю. Н., Черкасова Г. А., Уфимцева Н. В., Сорокин Ю. А., Тарасов Е. Ф. Русский ассоциативный словарь : в 2 т. М. : АСТАстрель, 2002. Т. 1.782 с. ; Т. 2.991 с.

САНРЯ - Словарь ассоциативных норм русского языка / под ред. А. А. Леонтьева. М. : Изд-во Моск. ун-та, 1977. 192 с.

EAT - Kiss G. R., Armstrong G., Milroy R. The Edinburgh Associative Thesaurus. Edinburgh : University of Edinburgh, 1972. $1539 \mathrm{p}$.

\section{REFERENCES}

Abaev V.I., 2006. Statyi po teorii i istorii yazykoznaniya [Articles on the Theory and History of Linguistics]. Moscow, Nauka Publ. $150 \mathrm{p}$.

Almyashova L.V., Monastyrskaya E.A., 2016. Sovremennye lingvisticheskie issledovaniya: yazykovaya aktualizatsiya kartiny mira [Modern Linguistic Research: Linguistic Actualization of the World Picture]. Kemerovo, KemTIPP Publ. 105 p.

Apresyan Yu.D., 2004. Predislovie [Preface]. Noviy obyasnitelniy slovar sinonimov russkogo yazyka. Vtoroe izdanie, ispravlennoe $i$ dopolnennoe [New Explanatory Dictionary of Synonyms of the Russian Language. Second Edition, Revised and Updated]. Moscow; Vena, Yazyki slavyanskoy kultury Publ.; Venskiy slavisticheskiy almanakh Publ. pp. 8-11 URL: http://www.lrc-lib.ru/ruslang/noss/intro.pdf

Balyasnikova O.V., 2015. Language as an Instrument of Conflict and Conflictogenic Linguistic Processes in the Modern World: Slavic Area. (Review). Aktualnye problemy Evropy [Urgent Problems of Europe], no. 1, pp. 194-213.

Balyasnikova O.V., Ufimtseva N.V., Cherkasova G.A., Chulkina N.L., 2018. Language and Cognition: Regional Perspective. Vestnik Rossiyskogo universiteta druzhby narodov. Seriya: 
Lingvistika [Russian Journal of Linguistics], vol. 22 , no. 2 , pp. 232-250. DOI: $10.223632312-$ 9182-2018-22-2-232-250.

Boas F., 1997. Istoriya i nauka v antropologii [History and Science in Anthropology]. Antologiya issledovaniy kultury [Anthology of Cultural Studies]. Saint-Petersburg, Universitetskaya kniga Publ., pp. 528-535.

Bogachev R.N., 2008. The Language Structure Factor in the Analysis of the Language Picture of the World. Nauchnaya mysl Kavkaza [Scientific Thought of Caucasus], no. 3, pp. 70-74.

Vaysgerber Y.L., 2009. Rodnoy yazyk i formirovanie dukha [Native Language and the Formation of the Spirit]. Moscow, LIBROKOM Publ. 232 p.

Vereshchagin E.M., Kostomarov V.G. 1973. Yazyk $i$ kultura. Lingvostranovedenie $v$ prepodavanii russkogo yazyka kak inostrannogo [Language and Culture: Linguistic and Cultural Studies in Teaching Russian as a Foreign Language]. Moscow, Moskovskiy Universitet Publ. 233 p.

Vorotnikov Yu.L., 2006. "Language Picture of the World": the Interpretation of the Concept. Znanie. Ponimanie. Umenie [Knowledge. Understanding. Skill], no. 2, pp. 88-90.

Hertz H., 1959. Printsipy mekhaniki, izlozhennye $v$ novoy svyazi [Principles of Mechanics Presented in a New Form]. Moscow, Akademiya nauk SSSR Publ. 386 p.

Gorobets A.F., 2008. Language and Cultural Pictures of the World: a Modern Approach to the Problem. Kulturnaya zhizn Yuga Rossii, no. 1 (26), pp. 11-13.

Humboldt W. von, 2018. Kontseptsiya obshchego yazykoznaniya: tseli, soderzhanie, struktura. Izbrannye perevody [The Concept of General Linguistics: Purpose, Content, Structure. Selected Translations]. Moscow, LENARD Publ. $504 \mathrm{p}$.

Demin I.V., 2018. Semioticheskiy povorot v naukakh o kulture [Semiotic Turn in Cultural Sciences]. Semioticheskiy povorot $v$ sotsialnogumanitarnom poznanii: istoki, predposylki, kulturnyy kontekst [Semiotic Turn in Social and Humanitarian Knowledge: Origins, Background, Cultural Context]. Samara, Samarskaya gumanitarnaya akademiya Publ., pp. 5-17.

Denisenko V.N., 2006. Semantic Field Method and World Language Picture (Nominations of Change in the Russian Language). Vestnik Rossiyskogo universiteta druzhby narodov. Seriya: Lingvistika [Russian Journal of Linguistics], no. 8, pp. 5-16.

Elenevskaya M.N., Ovchinnikova I.G., 2016. [The Storage and Description of the Verbal Associations]. Voprosy psikholingvistiki
[Journal of Psycholinguistics], no. 3 (29), pp. 69-92.

Zaliznyak A.A., Levontina I.B., Shmelev A.D., 2005. Klyuchevye idei russkoy yazykovoy kartiny mira [Key Ideas of the Russian Language Picture of the World]. Moscow, Yazyki slavyanskoy kultury. 540 p.

Zolotykh L.G., 2007. Kognitivno-diskursivnye osnovy frazeologicheskoy semantiki [Cognitive and Discursive Base of Phraseological Semantics]. Astrakhan, Astrakhanskiy universitet Publ. $265 \mathrm{p}$.

Karasik V.I., 2002. Yazykovoy krug: lichnost, kontsepty, diskurs [Language Circle: Personality, Concepts, Discourse]. Volgograd, Peremena Publ. 477 p.

Karaulov Yu.N., 1976. Obshchaya i russkaya ideografiya [General and Russian Ideography]. Moscow, Nauka Publ. 355 p.

Kolshanskiy G.V., 1990. Obyektivnaya kartina mira v poznanii $i$ v yazyke [Objective Picture of the World in Knowledge and Language]. Moscow, Nauka Publ. 108 p.

Kornilov O.A., 2003. Yazykovye kartiny mira kak proizvodnye natsionalnykh mentalitetov [Linguistic Pictures of the World as Derivatives of National Mentalities]. Moscow, CheRo Publ. $349 \mathrm{p}$.

Krapotina T.G., 2017. Ot kartiny mira realnoy k kartine mira metaforicheskoy: assotsiativno-obraznyy potentsial frazeologizma [From the Picture of the Real World to the Picture of the Metaphorical World: Associative and Figurative Potential of a Phraseological Unit]. Moscow, ASOU Publ. $158 \mathrm{p}$.

Lebedeva L.V., 2008. Modern Linguistic Approaches to the Study of the Linguistic Picture of the World. Voprosy kulturologii, no. 5, pp. 6-8.

Leontyev A.A., 1976. Psikholingvisticheskiy aspect yazykovogo znacheniya [Psycholinguistic Aspect of the Linguistic Meaning]. Printsipy $i$ metody semanticheskikh issledovaniy [Principles and Methods of Semantic Research]. Moscow, Nauka Publ., pp. 46-73.

Leontyev A.A., 1993. Yazykovoe soznanie i obraz mira [Language Consciousness and the Image of the World]. Yazyk i soznanie: paradoksalnaya ratsionalnost [Language and Consciousness: Paradoxical Rationality]. Moscow, Institute of Linguistics of the Russian Academy of Sciences Publ., pp. 16-21.

Leontyev A.A., 1996. Yazyk ne dolzhen byt "chuzhim" [Language should not be a "Stranger"]. Etnopsikholingvisticheskie aspekty prepodavaniya inostrannykh yazykov [Ethnopsycholinguistic Aspects of Teaching Foreign Languages]. Moscow, MMA im. 
I.M. Sechenova - Institut yazykoznaniya RAN Publ, pp. 41-47.

Leontyev A.N., 1981. Problemy razvitia psikhiki [Problems of the Psyche Development]. Moscow, MGU Publ. 584 p.

Leskina S.V., 2009. Russkie $i$ angliyskie frazeologizmy peyorativnoy semantiki kak otrazhenie yazykovoy kartiny mira [Russian and English Phraseologisms of Pejorative Semantics as a Reflection of the Linguistic Picture of the World]. Chelyabinsk, Atokso Publ. 148 p.

Magomedova D.M., 2008. Modern Interpretation of the Concept of "Linguistic Picture of the World". Izvestiya Dagestanskogo gosudarstvennogo pedagogicheskogo universiteta. Obshchestvennye i gumanitarnye nauki [Dagestan State Pedagogical University. Journal. Social and Human Sciences], no. 3 (4), pp.76-79.

Nikitenko Z.N., 2010. Shkolnoe obrazovanie v Evrope: Sovremennye tendentsii yazykovoy politiki [School Education in Europe: Modern Trends in Language Policy] (https://docviewer. yandex.ru/?url=ya-serp $\% 3 \mathrm{~A} \% 2 \mathrm{~F} \% 2$ Fteacher1.ucoz.com $\% 2 \mathrm{~F} \_1 \mathrm{~d} \% 2 \mathrm{~F} 0 \% 2 \mathrm{~F} 49$. pdf\&c $=558 \mathrm{af58188 \textrm {c } 4}$ (Accessed 23 June 2015).

Plank M., 1975. Izbrannye trudy. Termodinamika. Teoriya izlucheniya i kvantovaya teoriya. Teoriya otnositelnosti. Statyi i rechi [Elected Works. Thermodynamics. Radiation Theory and Quantum Theory. Theory of Relativity. Articles and Speeches]. Moscow, Nauka Publ. 788 p.

Pogorelaya E.A., 2006. Russkaya yazykovaya lichnost $v$ kontekste sotsiokulturnoy dinamiki postsovetskikh gosudarstv [Russian Language Personality in the Context of Social and Cultural Dynamics of the post-Soviet States]. Globalizatsiya-etnizatsiya: etnokulturnye $i$ etno-yazykovye protsessy: v. 2 kn. Kn. 2 [Globalization-Ethnization: Ethnocultural and Ethno-Linguistic Processes: in 2 Books. Book 2]. Moscow, Nauka Publ., pp. 360-386.

Postovalova V.I., 2014. Yazyk kak deyatelnost: Opyt interpretatsii kontseptsii Vilgelma fon Gumboldta [Language as an Activity: The Experience of Interpreting the Concept of Wilhelm von Humboldt]. Moscow, LENARD Publ. 256 p.

Postovalova V.I., 2017. Yazyk i miroponimanie: opyt lingvofilosofskoy interpretatsii [Language and Worldview. Experience of Linguophilosophical Interpretation]. Moscow, LENARD Publ. 312 p.

Mardieva L.A., Shchuklina T.Yu., eds., 2017. Regionalnaya kartina mira v yazykovoy kontseptualizatsii: dinamika kulturnykh smyslov: sbornik statey [Regional World Picture in Language Conceptualization: the Dynamics of Cultural Meanings: a Collection of Articles]. Kazan, Izd-vo Kazan. un-ta. 284 p.

Ufimtseva N.V. ed, 2017. Regionalnoe yazykovoe soznanie komi, russkikh i tatar: problemy vzaimovliyaniya [Regional Linguistic Consciousness of Komi, Russians and Tatars: Problems of Mutual Influence]. Moscow; Yaroslavl, Kantsler Publ. 240 p.

Serebrennikov B.A. ed., 1988. Rol chelovecheskogo faktora v yazyke. Yazyk i kartina mira [The Role of Human Factor in Language. Language and Worldview]. Moscow, Nauka Publ. 216 p.

Rubinshteyn S.L., 1998. Osnovy obshchey psikhologii [Basics of General Psychology]. Saint-Petersburg, Piter Publ. 705 p.

Demin I.V. ed., 2018. Semioticheskiy povorot v sotsialnogumanitarnom poznanii: istoki, predposylki, kulturnyy kontekst: kollektivnaya monografiya [Semiotic Turn in Social and Humanitarian Cognition: Origins, Background, Cultural Context. Collective Monograph]. Samara, Samarskaya gumanitarnaya akademiya Publ. 270 p.

Stepanov Yu.S., 1997. Konstanty: Slovar russkoy kultury [Constants: Dictionary of Russian culture]. Moscow, Yazyki russkoy kultury Publ. $824 \mathrm{p}$.

Sukhareva Yu.V., 2012. [Interdependence of the Picture of the World and Language Picture of the World]. Vestnik Juzhno-Uralskogo gosudarstvennogo universiteta [Bulletin of the South Ural State University. Series "Linguistics"], no. 2, pp. 110-113.

Toporov V.N., 1992. Model mira [Model of the World.]. Mify, narodov mira. Entsiklopediya [Myths of Nations of the World]. Moscow, Sovetskaya Entsiklopediya. Vol. 2, pp. 161-164.

Uorf B.L., 1960. Nauka i yazykoznanie [Science and Linguistics]. Novoe $v$ lingvistike [New in Linguistics]. Moscow, Inostrannya literatura Publ. Iss. 1, pp. 169-182.

Uryson E.V., 2003. Problemy issledovaniya yazykovoy kartiny mira: Analogiya v semantike [Problems of Studying the Language Picture of the World: Analogy in Semantics]. Moscow, Yazyki slavyanskoy kultury. $223 \mathrm{p}$.

Ufimtseva N.V., 2013. Ferdinand de Saussures Ideas from the Psycholinguistic Perspective. Voprosy psikholingvistiki [Journal of Psycholinguistics], no. 17 , pp. 44-52.

Ufimtseva N.V., 2016. Language Picture of the World: the Problem of Modeling. Voprosy psikholingvistiki [Journal of Psycholinguistics], no. 27 , pp. 238-249.

Heidegger M., 1986. Vremya kartiny mira [The Age of the World Picture]. Novaya tekhnokraticheskaya volna na Zapade [A New Technocratic Wave in the West]. Moscow, Progress Publ., pp. 85-118. 
Khizhnyak S.P., 2016. National Culture as a Factor of Forming Linguistic and Conceptual Pictures of the World (on the Example of Scientific World Picture in Jurisprudence). Izvestiya Saratovskogo universiteta. Novaya seriya. Seriya Filologiya. Zhurnalistika [Izvestiya of Saratov University. New Series. Series: Philology. Journalism], vol. 16, no. 2, pp. 130-134.

Tsennostnaya kartina mira: lingvokulturnye aspekty, 2016 [Value Picture of the World: Linguistic and Cultural Aspects], Volgograd, Paradigma; Tianjin, [b. i.]. 306 p.

Chulikov Yu.M., 2010. Fairy-tale Picture of the World as a Fragment of Folklore Linguistic Picture of the World. Vestnik Pyatigorskogo gosudarstvennogo lingvisticheskogo universiteta [Pyatigorsk State Linguistic University Bulletin], no. 4, pp. 147-151.

Chupryna O.G., 2011. "Peace" and "Kinship" in AngloSaxon Language Model of World. Teoriya $i$ praktika obshchestvennogo razvitiya [Theory and Practice of Social Development], no. 7, pp. 337-339.

Shpilnaya N.N., 2017. Yazykovaya kartina mira $v$ strukture rechemyslitelnoy deyatelnosti [Language Picture of the World in the Structure of Speech-Thinking Activity]. Moscow, LENARD Publ. $152 \mathrm{p}$.

Yuzdova L.P., 2009. Adverbial Qualitative Phraseological Units as means of Reflecting the Russian Language Picture of the World. Vestnik Chelyabinskogo gosudarstvennogo universiteta [Bulletin of Chelyabinsk State University], no. 17 (155), pp. 119-123.

Azab C., Clark T. 2017. Speak my Language or Look Like me? - Language and Ethnicity in Bilingual Customer Service Recovery. Journal of Business Research, vol. 72. pp. 57-68.

Baydak A.V., Scharioth C., Ilyashenko I.A., 2015. Interaction of Language and Culture in the Process of International Education. ProcediaSocial and Behavioral Sciences. Vol. 215: International Education and Cross-Cultural Communication, Problems and Solutions, (IECC 2015): International Conference, 911 June 2015, Tomsk, Russia: [proceedings]. Tomsk, pp. 14-18.

Bekova Z.K., 2013. Ethnic Picture of the World and Its Influence upon the Process of Adaptation in Higher Educational Establishments. $4^{\text {th }}$ World Conference on Psychology, Counseling and Guidance WCPCG-2013, 2426 May 2013, Kultur University. Turkey, Istanbul, pp. 939-943.

Chakyroglu A.K., Suiyerkul B., 2014. Representation of the Concept "Hospitality" in the Kazakh
Language. Procedia - Social and Behavioral Sciences, vol. 136, pp. 124-128.

Debrenne M., Ufimtseva N., 2011. Lapport des Dictionnaires D'associations Lexicales aux Études de Sémantique. Syntaxe et Sémantique, no. 12, pp. 121-137.

Faizah S., 2016. Psycholinguistic Determinants of Immigrant Second Language Acquisition. Lingua, vol. 179, pp. 24-37.

Keith A., 2010. Vantage Theory and Linguistic Relativity. Language Sciences, vol. 32, iss. 2, pp. 158-169.

Kent G.H., Rosanoff, A.J., 1910. A Study of Association in Insanity. American Journal of Insanity, vol. 67, no. 1-2, pp. 37-96, 317-390.

Khorechko U.V., Khorechko U.V., Sentsov A.E., Ruchina A.V., Bolsunovskaya L.M., Kazaryan A.A., 2015. The Concept of "Tea" in the Language Picture of the World (Based on the Chinese and Russian Languages). ProcediaSocial and Behavioral Sciences. The XXVI Annual International Academic Conference, Language and Culture, 27-30 October 2015. Vol. 200, pp. 215-223.

Lau H.T., Lee R., 2018. Ethnic Media Advertising Effectiveness, Influences and Implications. Australian Marketing Journal. Vol. 26, pp. 216-220.

Lucy J.A., 2015. Sapir-Whorf Hypothesis. International Encyclopedia of the Social \& Behavioral Sciences. $2^{\text {nd }}$ Ed. Oxford, Elsevier, pp. 903-906.

Rosa J., 2016. Racializing Language, Regimenting Latinas/os: Chronotope, Social Tense, and American Raciolinguistic Futures. Language and Communication, vol. 46, pp. 106-117.

Sharifian F., 2017. Cultural Linguistics and Linguistic Relativity. Language Sciences, vol. 59, pp. 83-92.

Strotkina T., Gillespie D., 2014. An Onomastic Approach to the Works of A. Ivanov as a Reflection of the Artistic Picture of the World. Procedia - Social and Behavioral Sciences. The XXV Annual International Academic Conference, Language and Culture, 2022 October 2014. Vol. 154, pp. 272-275.

Taylor T.J., 2013. Calibrating the Child for Language: Meredith Williams on a Wittgensteinian Approach to Language Socialization. Language Sciences, vol. 40, pp. 308-320.

\section{DICTIONARIES}

Ufimtseva N.V., Cherkasova G.A. Russian Regional Associative Dictionary (European Part of 


\section{ГЛАВНАЯ ТЕМА НОМЕРА}

Russia). In 2 parts. Part 1. From Stimulus to Reaction. Moscow, Moskovskaya mezhdunarodnaya akademiya Publ., 2018. 544 p.; Part 2. From Reaction to Stimulus. Moskovskaya mezhdunarodnaya akademiya Publ., 2019.688 p. Apresyan Yu.D., ed. New Explanatory Dictionary of Russian Synonyms. Second Edition, Revised and Updated. Moscow; Vienna, Yazyki slavyanskoy kultury; Venskiy slavisticheskiy almanakh, 2004. 1488 p. URL: http://www.lrc-lib.ru/ruslang/noss/ intro.pdf
Karaulov Yu.N., Cherkasova G.A., Ufimtseva N.V., Sorokin Yu.A., Tarasov E.F. Russian Associative Dictionary. In 2 vols. Moscow, AST-Astrel Publ., 2002.991 p.

Leontyeva A.A., ed. Dictionary of Associative Norms of the Russian Language. Moscow, Izd-vo Mosk. unta, 1977. 192p.

Kiss, G.R., Armstrong, G., Milroy, R., 1972. The Edinburgh Associative Thesaurus. University of Edinburgh. URL: https://w3id. org/ associations/eat.nt.gz

\section{Information about the Authors}

Natalya V. Ufimtseva, Doctor of Sciences (Philology), Professor, Head of Ethnopsycholinguistics Sector, Institute of Linguistics, Russian Academy of Sciences, Bolshoy Kislovskiy Pereulok, 1, 125009 Moscow, Russia, nufimtseva@yandex.ru, https://orcid.org/0000-0002-7476-8421

Olga V. Balyasnikova, Candidate of Sciences (Philology), Senior Researcher of Ethnopsycholinguistics Sector, Institute of Linguistics, Russian Academy of Sciences, Bolshoy Kislovskiy Pereulok, 1, 125009 Moscow, Russia; Associate Professor, Sechenov First Moscow State Medical University, Institute of Linguistics and Intercultural Communication, Trubetskaya St., 8-2, 119991 Moscow, Russia, o.balyasnikova@iling-ran.ru, https://orcid.org/0000-0002-5501-5264

\section{Информация об авторах}

Наталья Владимировна Уфимцева, доктор филологических наук, профессор, заведующая сектором этнопсихолингвистики, Институт языкознания РАН, Большой Кисловский переулок, 1, 125009 г. Москва, Россия, nufimtseva@yandex.ru, https://orcid.org/0000-0002-7476-8421

Ольга Вениаминовна Балясникова, кандидат филологических наук, старший научный сотрудник сектора этнопсихолингвистики, Институт языкознания РАН, Большой Кисловский переулок, 1, 125009 г. Москва, Россия; доцент, Института лингвистики и межкультурной коммуникации, Первый МГМУ им. И.М. Сеченова, ул. Трубецкая 8-2, 119991 г. Москва, Россия, o.balyasnikova@ilingran.ru, https://orcid.org/0000-0002-5501-5264 